\title{
Role of the JAK2/STAT pathway and losartan in human glomerular mesangial cell senescence
}

\author{
HONGLI ZHOU ${ }^{1,3}$, BO HUANG ${ }^{2}$, JUAN DU $^{1}$ and LINING WANG ${ }^{1}$ \\ ${ }^{1}$ Department of Nephropathy, First Affiliated Hospital of China Medical University, Shenyang, Liaoning 110001; \\ ${ }^{2}$ Department of Thoracic Surgery, First Affiliated Hospital of Liaoning Medical College, Jinzhou, Liaoning 121001, P.R. China
}

Received December 3, 2009; Accepted February 16, 2010

DOI: 10.3892/mmr_00000270

\begin{abstract}
Glomerular mesangial cells (GMCs) have a finite cell lifespan and eventually enter irreversible growth arrest known as cellular senescence. The functional changes associated with cellular senescence are thought to contribute to human aging and age-related kidney disorders, such as chronic kidney disease. Angiotensin II (AngII), a principal effector of the renin-angiotensin system (RAS), is known to promote aging and cellular senescence. The cellular and molecular mechanisms responsible for the senescence of GMCs remain largely undefined. The JAK2/STAT pathway plays a pivotal role in transmitting cytokine signals. To date, little is known regarding the relationship between AngII or STAT protein and aging human GMCs. Therefore, this study was designed to determine the effects of AngII and the JAK2/STAT pathway on the process of GMC aging. We observed the functions of the AngII receptor blocker losartan and the JAK2 blocker AG490 in delaying GMC aging. Cells were assigned to a control group, an AngII-induced group, a losartan + AngIIstimulated group and an AG490 + AngII-treated group. AngII promoted growth arrest with phenotypic characteristics of cell senescence, such as enlarged cell morphology, polymorphic nuclei and vacuolization, increased staining for senescenceassociated $\beta$-galactosidase, and depressed cell proliferation. The JAK2/STAT1/3 pathway is drastically activated in AngIIinduced senescence cells. Compared to the AngII-induced group, in the cells treated with losartan and AG490, the characteristics of cell senescence were ameliorated, and the
\end{abstract}

Correspondence to: Professor Lining Wang, Department of Nephropathy, The First Affiliated Hospital of China Medical University, No. 155, Nanjing North Street, Heping, Shenyang, Liaoning 110001, P.R. China

E-mail: liningwang1956@126.com

Present address: ${ }^{3}$ Department of Nephropathy, The First Affiliated Hospital of Liaoning Medical College, Jinzhou, Liaoning, P.R. China

Key words: angiotensin II, senescence, glomerular mesangial cells, JAK2/STAT pathway expression of STAT1, STAT3, pSTAT1 and pSTAT3 was decreased. Our results suggest that AngII induces human GMC senescence, and that the JAK2/STAT1/3 pathway is involved in this process. By applying losartan and blocking the JAK2/STAT pathway, it may be possible to delay GMC aging.

\section{Introduction}

Aging is associated with a degenerative effect on many organs, including the kidney. Studies confirm the near exponential rise in chronic kidey disease with age, and the need for renal replacement therapy among these patients is rapidly increasing (1-4). The molecular basis of age-related changes in the kidney is unknown; however, organ aging may reflect aspects of cellular senescence. Glomerular mesangial cells (GMCs) are the most important and active cells of the kidney, regulating renal blood flow, excreting extracellular matrix and mediating inflammation. Changes in the phenotype and function of GMCs must produce considerable effect. Angiotensin II (AngII), a major component of the renin-angiotensin system (RAS), plays a primary role as a vasoconstrictor in controlling renal homeostasis. Besides its action as a potent hypertensive hormone, AngII has various biological effects on cell proliferation, migration and invasion. Recent evidence suggests that AngII may play an important role in aging (5-7). Previous studies have shown that cultured endothelial cells exposed to AngII undergo arrest in the $\mathrm{G}_{1}$ phase of the cell cycle, with increased expression of the cyclin-dependent kinase (CDK) inhibitors p21 and p27, which are markers of cell senescence (8-10). It has been reported that angiotensin converting enzyme inhibitors (ACEIs) and AngII receptor blockers (ARBs) have not only hypotensive, but also protective effects on the progression of kidney aging (11-13).

The cellular and molecular mechanisms responsible for the senescence of GMCs remain largely undefined, and the upstream elements involved in the signaling pathways are presently unknown. Among these signaling molecules, the signal transducers and activators of transcription (STATs) are proteins that play a pivotal role in transmitting cytokine signals. Inactive cytoplasmic STATs are activated through tyrosine phosphorylation and dimerize before translocating into the nucleus to activate the transcription of the target gene. Among the seven members of the mammalian STAT 
family, STAT1 and STAT3 have been the most strongly implicated in the genesis of aging $(14,15)$. Previous studies have shown that AngII activates STAT1 and STAT3 signaling in various cells (16-19). Changes in STAT1 and STAT3 protein vary among aging cells (20). To date, nothing is known regarding the relationship between aging human GMCs and STAT protein.

We hypothesized that AngII may induce human GMC senescence. We further investigated whether AngII induces human GMC senescence via the JAK2/STAT pathway, and examined the function of losartan in delaying GMC aging. Additionally, we examined age-related changes after treatment with AG490, the specific blocker for JAK2. Elucidation of the mechanisms underlying these changes may provide valuable insight into the sequence of events that occurs during the establishment of the senescent phenotype.

\section{Materials and methods}

Materials. Human mesangial cell medium was from the American Science Cell Co. Rabbit monoclonal antibodies specific for STAT1, STAT3, pSTAT1 and pSTAT3 were obtained from Cell Signaling Technology. AngII and AG490 were from Sigma, and losartan was kindly provided by Merck.

Cell culture. Mesangial cells were obtained from ScienCell Research Laboratories (Carlsbad, CA, USA) and cultured in mesangial cell medium supplemented with $10 \%$ fetal bovine serum, $100 \mathrm{U} / \mathrm{ml}$ penicillin and $100 \mu \mathrm{g} / \mathrm{ml}$ streptomycin at $37^{\circ} \mathrm{C}$ in a humidified atmosphere of $5 \% \mathrm{CO}_{2}$ in air. The cells were grown to $80-90 \%$ confluence in $25-\mathrm{cm}^{2}$ culture flasks and subcultured at a ratio of 1:2. Cells from passages 5-8 were used. For the experiments, the cells were seeded and grown for $24 \mathrm{~h}$, then maintained in serum-free medium for $12 \mathrm{~h}$ to ensure $\mathrm{G}_{0}$ arrest. At this point, a final concentration of AngII $\left(10^{-6} \mathrm{~mol} / \mathrm{l}\right)$ was added to the culture medium, and cells were stimulated for $72 \mathrm{~h}$. Losartan $\left(10^{-5} \mathrm{~mol} / \mathrm{l}\right)$ and AG490 (10 $\mu \mathrm{mol} / \mathrm{l})$ were added $1 \mathrm{~h}$ prior to the addition of AngII. Medium overlying the cells was supplemented with AngII, losartan or AG490 on alternate days.

Cell viability assay. To assess cell viability, $1 \times 10^{3}$ cells/well were seeded in 96-well microtiter plates and allowed to adhere to the plate for $24 \mathrm{~h}$. Cells were then treated with $10^{-8}, 10^{-7}, 10^{-6}$, $10^{-5}$ or $10^{-4} \mathrm{~mol} / \mathrm{l}$ AngII (6 wells/group). After incubation for 24 , 48, 72 and $96 \mathrm{~h}$, respectively, $20 \mu \mathrm{l}$ of $5 \mathrm{mg} / \mathrm{ml} \mathrm{3-(4,5-dimeth-}$ ylthiazol-2-yl)-2,5-diphenyl tetrasodium bromide (MTT) was added to each well, and cells were incubated for an additional $4 \mathrm{~h}$ at $37^{\circ} \mathrm{C}$. Dimethyl sulfoxide $(150 \mu \mathrm{l})$ was added to the wells to dissolve the formazan crystals. Absorbance (optical density, OD) was measured at $570 \mathrm{~nm}$. The percentage of live cells was calculated as the OD of experimental cells/OD of control cells x 100 .

Senescence-associated $\beta$-galactosidase staining. The senescence of cells was verified by in situ staining for senescence-associated $\beta$-galactosidase (SA- $\beta$-gal), as previously described. Briefly, cells growing on 24-well microtiter plates were washed three times with phosphate-buffered saline (PBS), then fixed with
$2 \%$ formaldehyde/2\% glutaraldehyde in PBS for 3-5 min at room temperature. The cells were then washed again and incubated overnight at $37^{\circ} \mathrm{C}$ (without $\mathrm{CO}_{2}$ ) with freshly prepared SA- $\beta$-gal staining solution containing $1 \mathrm{mg} / \mathrm{ml} \mathrm{X-gal,} 40 \mathrm{mM}$ citric acid/sodium phosphate ( $\mathrm{pH} 6.0), 5 \mathrm{mM}$ potassium ferrocyanide, $5 \mathrm{mM}$ potassium ferricyanide, $150 \mathrm{mM} \mathrm{NaCl}$ and $2 \mathrm{mM} \mathrm{MgCl}_{2}$. Cells were then rinsed with PBS, and 100-200 cells in six microscopic fields were counted to determine the percentages of SA- $\beta$-gal positively stained cells.

Cell cycle analysis. To analyze the cell cycle profile, cells were digested with $0.25 \%$ trypsinase, washed with PBS and fixed in $70 \%$ methanol at $4^{\circ} \mathrm{C}$ overnight. Cells were then resuspended in PBS with RNase A $(100 \mathrm{~g} / \mathrm{ml})$ and incubated for $30 \mathrm{~min}$ at $37^{\circ} \mathrm{C}$. Then, the cells were stained with propidium iodide $(20 \mu \mathrm{g} / \mathrm{ml})$ for $30 \mathrm{~min}$ and analyzed by FACScan flow cytometry using linear amplification. For each sample, 20,000 events were collected, and aggregated cells were gated out. Data were analyzed by auto-analysis function ModFitLT3.0 software.

Optical microscopy and ultra-microstructure. Morphologic changes in the senescent cells were evaluated using optical microscopy. Cells were washed twice with PBS and examined using an Olympus optical microscope. Transmission electron microscopy was used to evaluate the ultra-microstructure. Cells were washed twice with PBS and fixed in $2.5 \%$ glutaraldehyde in $0.2 \mathrm{M}$ cacodylate buffer $(\mathrm{pH} 7.4)$ at $4^{\circ} \mathrm{C}$ for $2 \mathrm{~h}$, then washed in PBS and postfixed in $1 \% \mathrm{OsO}_{4}$ for $1 \mathrm{~h}$. After washing in PBS, the samples were dehydrated in a graded series of ethanol and acetone, and embedded in Epon 812. Ultrathin sections (70-nm) were cut on a Leica Ultracut UCT Ultramicrotome. After staining with uranyl acetate and lead citrate, the sections were examined using a Hitachi H500 transmission electron microscope at $75 \mathrm{kV}$.

Immunofluorescence detection. Expression of STAT1, STAT3, pSTAT1 and pSTAT3 was analyzed by immunofluorescence staining. Briefly, cells were cultured on glass slides for $72 \mathrm{~h}$, then fixed with ice-cold $4 \%$ formalin solution in PBS for $10 \mathrm{~min}$ at $4^{\circ} \mathrm{C}$. After blocking with $3 \%$ hydrogen peroxide for $10 \mathrm{~min}$ and $5 \%$ bovine serum albumin for $2 \mathrm{~h}$, they were incubated with monoclonal rabbit antibodies against human STAT1, STAT3, pSTAT1 and pSTAT3 overnight at $4^{\circ} \mathrm{C}$, and then with a goat anti-rabbit $\operatorname{IgG}$ at $37^{\circ} \mathrm{C}$ for $1 \mathrm{~h}$ after extensive washing between each step. Monoclonal rabbit antibodies against human STAT1, STAT3 and pSTAT1, pSTAT3 dilutions were used as recommended by the manufacturers.

Western blot analysis. At each time point (0, 24, 48, 72, 96 and $120 \mathrm{~h}$ ) cells were lysed on ice in lysis buffer, then PMSF was added. Cell extracts were collected after supersonic quassation and centrifugation of the cell lysates at 12,000 $\mathrm{x}$ g for $5 \mathrm{~min}$ at $4^{\circ} \mathrm{C}$. Protein concentration was determined with a BCA protein assay reagent kit. An equal amount of protein (20 $\mu \mathrm{g} /$ lane) from each cell extract was resolved on an $8 \%$ SDS-PAGE gel and electroblotted onto a PVDF membrane. Blots were blocked with TBS-T blocking buffer (5\% non-fat milk in $25 \mathrm{mM}$ Tris- $\mathrm{HCl}$, pH 8.0, $3 \mathrm{mM} \mathrm{KCl}, 150 \mathrm{mM} \mathrm{NaCl}$ and $0.05 \%$ Tween), and subsequently probed with a relevant 
primary antibody at a predetermined optimal concentration for $2 \mathrm{~h}$ at room temperature. After three washes with TBS-T, the immunoblots were incubated with an appropriate peroxidase-conjugated secondary antibody for $1 \mathrm{~h}$ at room temperature, then developed using an ECL Western blotting detection system and recorded by exposure to X-ray film.

Statistical analysis. Data were expressed as the means \pm standard deviation (SD). Differences were evaluated by ANOVA. Statistical significance was defined as $\mathrm{p}<0.05$.

\section{Results}

Cell viability assay. To evaluate cell viability, we examined the various concentrations of AngII required to induce cellular senescence in GMCs during a 96-h period. Using MTT assays, we demonstrated that cellular proliferation was slightly higher in the AngII-induced groups than in the control group after 24 or $48 \mathrm{~h}$ of incubation. After $72 \mathrm{~h}$ of incubation, cellular proliferation was permanently inhibited in the AngII-induced groups, with an OD value significantly lower than that of the control group (Fig. 1). Viability with $10^{-6} \mathrm{~mol} / \mathrm{l}$ AngII was $81.09 \pm 4.52 \%$ ( $\left.<<0.01\right)$. There was no significant difference between the viability of cells stimulated with $10^{-7}$ and $10^{-8} \mathrm{~mol} / \mathrm{l}$ AngII and the control cells, whereas the viability of cells stimulated by $10^{-4}$ and $10^{-5} \mathrm{~mol} / \mathrm{l}$ AngII was decreased compared to the control cells $(49.13 \pm 3.32$ and $51.18 \pm 3.48 \%$; $\mathrm{p}<0.01)$. Therefore, the senescent model of GMCs was established using $10^{-6} \mathrm{~mol} / \mathrm{l}$ AngII.

AngII-induced GMC senescence. We first determined whether AngII stimulates the cellular senescence of GMCs using SA- $\beta$-gal staining, a reliable biomarker for cellular senescence. Increased staining of SA- $\beta$-gal has been reported in aging cells when these have been assayed at a near-neutral $\mathrm{pH}$ of 6.0. In the present study, SA- $\beta$-gal staining was significantly increased in the AngII-induced cells compared to the control cells $(83.10 \pm 6.71$ and $3.18 \pm 0.04 \%$; $<<0.01)$ (Fig. 2A and B). This indicates that AngII promoted cellular senescence in GMCs. Flow cytometry was used to characterize the nature of cell cycle arrest. The cell cycle was arrested at the $\mathrm{G}_{0} /$ $\mathrm{G}_{1}$ phase in the AngII-induced group $(91.36 \pm 6.45 \%)$ as compared to the control cells $(60.13 \pm 3.15 \%, \mathrm{p}<0.05)$. The $\mathrm{S}$ and $\mathrm{G}_{2} / \mathrm{M}$ phases tended to disappear in AngII-induced cells as compared to the control cells $(6.52 \pm 0.42$ and $2.12 \pm 0.33 \% ; 24.91 \pm 1.16$ and $14.96 \pm 0.96 \%$, respectively; $\mathrm{p}<0.05$ ) (Fig. 3A and B). These results indicated that the cells were arrested by AngII at the $G_{0} / G_{1}$ phase. Optical and transmission electron microscopy were used to evaluate morphologic and ultra-microstructure alterations in the GMCs. Senescent cells were characterized by enlarged cell morphology, polymorphic nuclei, chromatin condensation at the nuclear margin, invagination of the nuclear membrane, the disappearance of mitochondria and pulp-lysosome identified in aging cells (Fig. 4B and F). The control cells had a round and smooth morphology, and even chromatin distribution (Fig. 4A and E).

Increase in STAT1/3 during aging. To determine changes in STAT1/3 during the process of GMC senescence stimulated

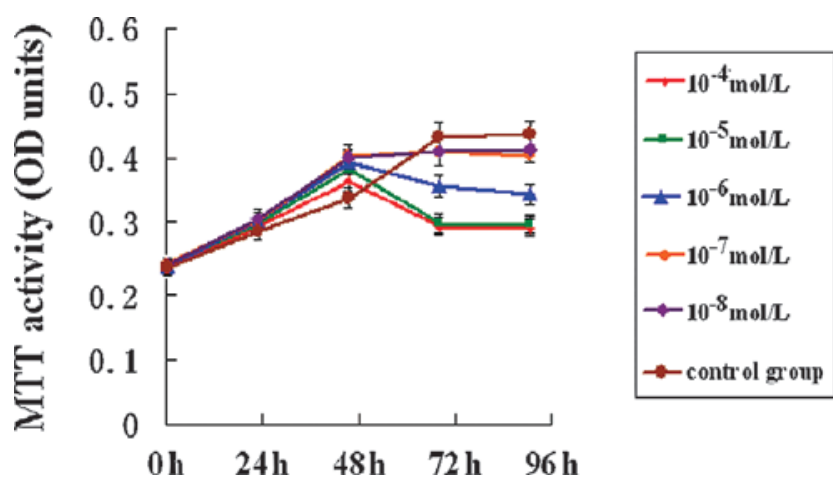

Figure 1. Effect of various concentrations of AngII on the proliferation of GMCs. Values are the means \pm SD $(n=6) ;{ }^{*} p<0.01$ vs. the control group.
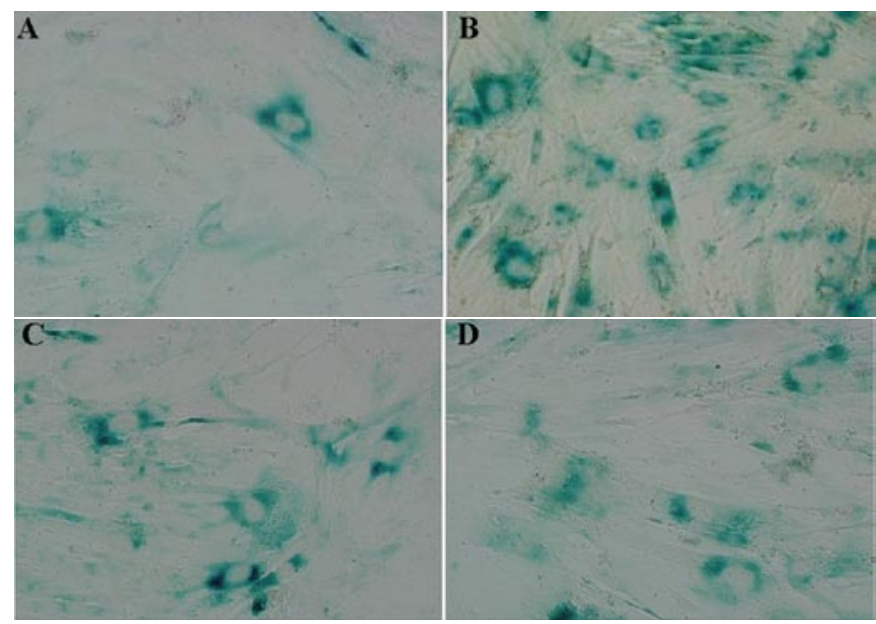

Figure 2. Senescence-associated- $\beta$-galactosidase activity in GMCs. (A) Control cells, (B) AngII-induced senescent cells, (C) losartan + AngII-stimulated cells and (D) AG490 + AngII-treated cells. Original magnification, x200. Results are representative of two regions from three independent experiments.
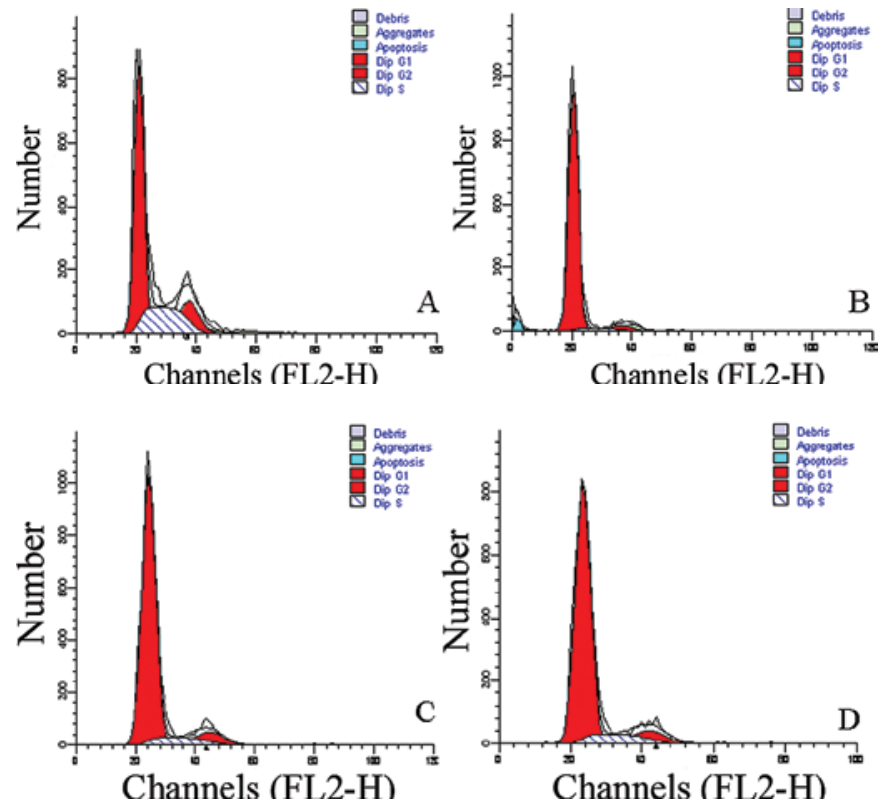

Figure 3. Flow cytometric cell cycle analysis of (A) control cells, (B) AngIIinduced senescent cells, (C) losartan + AngII-stimulated cells and (D) AG490 + AngII-treated cells. Red, $\mathrm{G}_{1}$ phase; blue, $\mathrm{S}$ phase; small red area, $\mathrm{G}_{2} / \mathrm{M}$ phase. Typical results of three independent experiments are shown. 


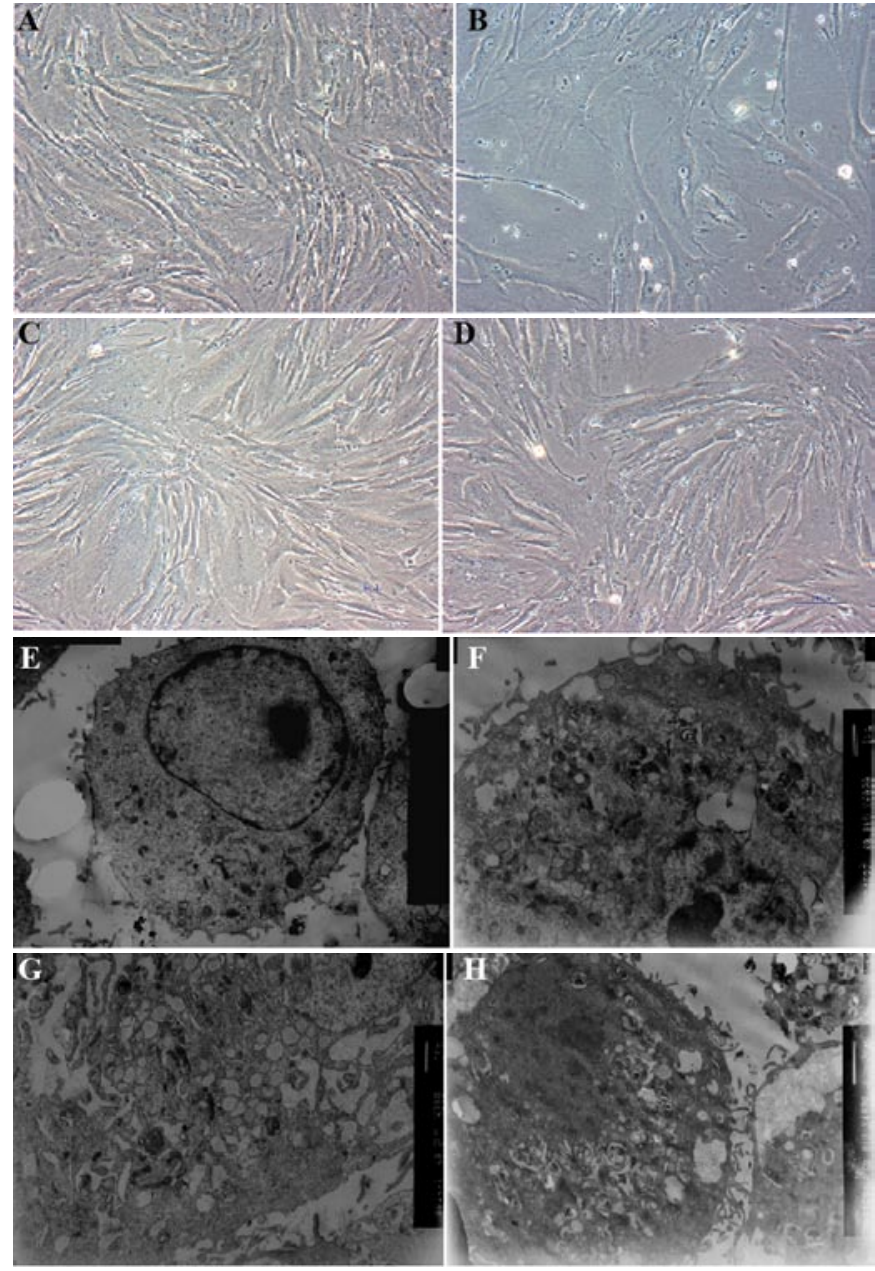

Figure 4. Images of (A) control cells, (B) AngII-induced senescent cells, (C) losartan + AngII-stimulated cells and (D) AG490 + AngII-treated cells captured under an optical microscope. Original magnification, x100. Images of (E) control cells, (F) AngII-induced senescent cells, (G) losartan + AngII-stimulated cells and (H) AG490 + AngII-treated cells captured with a transmission electron microscope. Original magnification, x6,000 (E,F,G); $\mathrm{x} 4,000(\mathrm{H})$. Typical results of three independent experiments are shown.

by AngII, immunofluorescence detection and Western blot analysis were performed. AngII selectively induced STAT1 and STAT3 activation in the GMCs. The exposure of the cells to $10^{-6} \mathrm{~mol} / \mathrm{l}$ AngII resulted in the activation of STAT1 and STAT3, as manifested by an increase in STAT phosphorylation. Using immunofluorescence detection, we found that STAT1, STAT3, pSTAT1 and pSTAT3 were expressed in the cytoplasm and cytoblast in normal GMCs, and were increased in AngII-induced aging cells, in particular in the cytoblast (Fig. 5). Western blot analysis indicated that STAT1, STAT3, pSTAT1 and pSTAT3 levels were also increased in the aging cells compared to the control cells. Upon exposure to losartan and AG490, STAT expression in the aging cells was decreased (Fig. 6). As shown in Fig. 7, the increase in STAT3 and pSTAT3 peaked at $48 \mathrm{~h}$ and lasted for $72 \mathrm{~h}$, declining to the basal level at $96 \mathrm{~h}$ after exposure to AngII. The increase in STAT1 and pSTAT1 peaked at $24 \mathrm{~h}$ and lasted for $72 \mathrm{~h}$, declining to the basal level at $96 \mathrm{~h}$ after exposure to AngII. These results suggest that the exposure of GMCs to AngII activates STAT1 and STAT3.

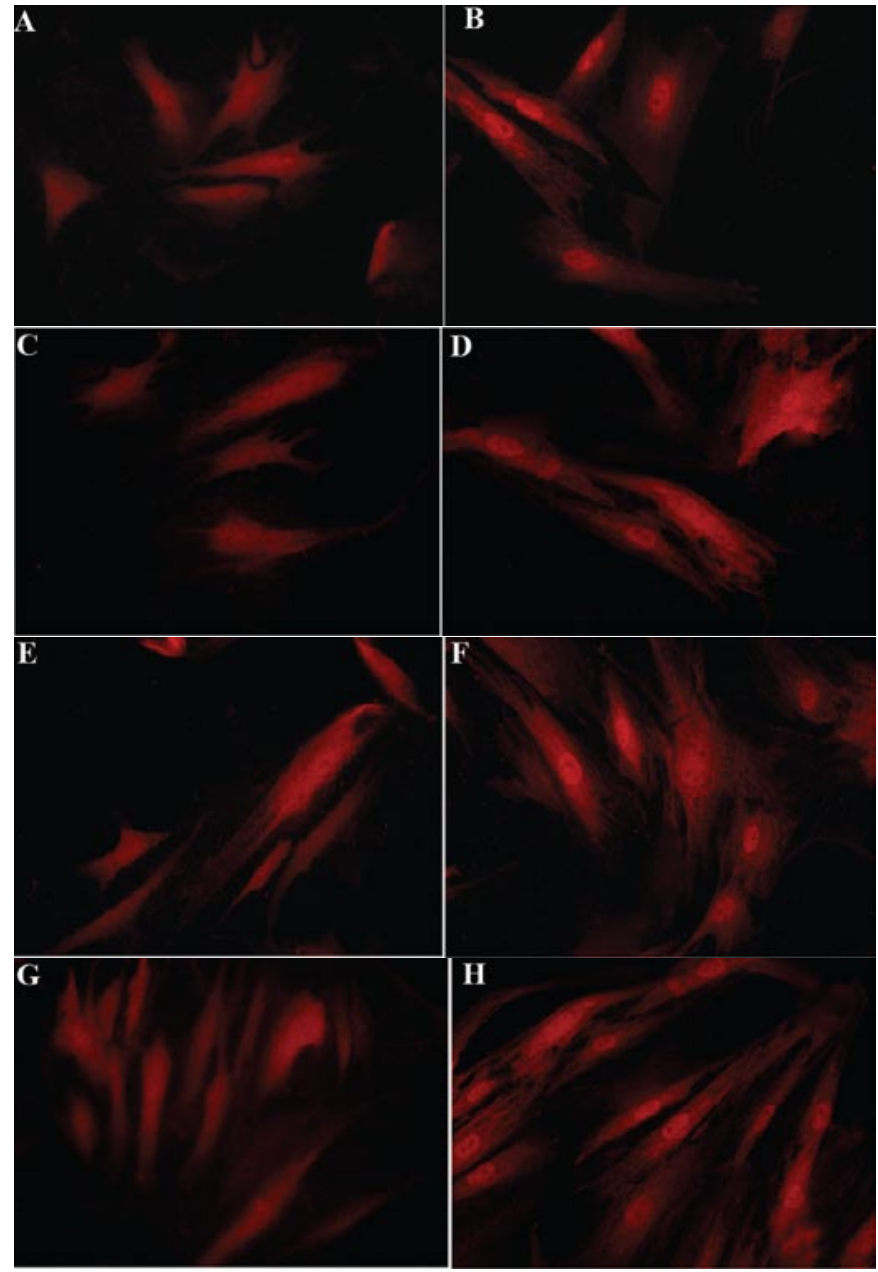

Figure 5. Immunofluorescence staining of STAT1, STAT3, pSTAT1 and pSTAT3 expression in GMCs. Cytoplasm- and cytoblast-positive cells are stained red. Original magnification, $x 400$. STAT1 in (A) control cells and (B) AngII-induced senescent cells; pSTAT1 in (C) control cells and (D) AngII-induced senescent cells. STAT3 in (E) control cells and (F) AngIIinduced senescent cells. pSTAT3 in (G) control cells and (H) AngII-induced senescent cells.

Function of losartan in delaying GMC aging. MTT assays demonstrated that the cellular proliferation capacity of GMCs was ameliorated in cells exposed to losartan. OD values were higher in these cells than in the aging cells stimulated with AngII. Cell viability was $94.95 \pm 5.12 \%$. SA- $\beta$-gal staining was decreased in the losartan + AngII-stimulated group as compared to the AngII-induced group $(42.13 \pm 3.61$ and $83.10 \pm 6.71 \%$; $\mathrm{p}<0.01$ ) (Fig. 2B and C). Cell cycle analysis indicated that the cell percentage at the $\mathrm{G}_{0} / \mathrm{G}_{1}, \mathrm{~S}$ and $\mathrm{G}_{2} / \mathrm{M}$ phases was normalized (Fig. 3B and C). Optical microscopy and transmission electron microscopy revealed losartan + AngII-stimulated cells to be regularly aligned, with decreased pulp-lysosome and a smooth nuclear membrane (Fig. 4C and G).

Function of blocking JAK2/STAT in delaying GMC aging. MTT assays demonstrated that the cellular proliferation capacity of GMCs was ameliorated in cells exposed to AG490. OD values were higher in these cells than in the aging cells stimulated by AngII. Cell viability was $95.61 \pm 5.12 \%$. SA- $\beta$-gal staining was decreased in the AG490 + AngII-stimulated 


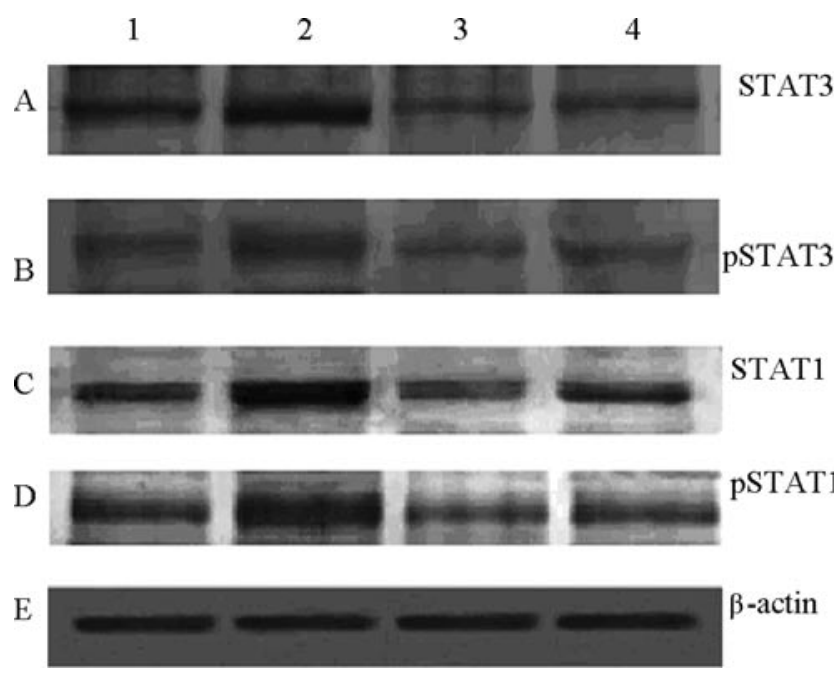

Figure 6. Western blot analysis of STAT3, pSTAT3, STAT1 and pSTAT1 expression. Lane 1, control cells; 2, AngII-induced senescent cells; 3, losartan + AngII-stimulated cells; 4, AG490 + AngII-treated cells.

group as compared to the AngII-induced group (46.28 \pm 3.73 and $83.10 \pm 6.71 \% ; \mathrm{p}<0.01$ ) (Fig. $2 \mathrm{~B}$ and D). Cell cycle analysis indicated that the cell percentage at the $\mathrm{G}_{0} / \mathrm{G}_{1}, \mathrm{~S}$ and $\mathrm{G}_{2} / \mathrm{M}$ phases was near to normal (Fig. 3B and D). Optical microscopy and transmission electron microscopy revealed AG490 + AngII-stimulated cells to be regularly aligned, with nuclear membrane invagination and a decreased pulp-lysosome (Fig. 4D and H).

\section{Discussion}

The natural process of aging is associated with the progressive modification and, ultimately, the loss of organ function. The kidney is also affected by the aging process. Much attention has been devoted to the study of the effects of aging on the kidney. It is well known that kidney function is slightly decreased with aging. The kidney exhibits greater ageassociated deterioration than most organs, even in the absence of cardiovascular disease (21). Age-associated changes in the kidney are important, not only because normal aging alters renal function, but also because of the high frequency of end-stage renal disease (ESRD) in the elderly. The number of patients with ESRD in the Western world is progressively increasing due to an increase in the number of patients over 65 years of age (22). Understanding the mechanisms of declining organ function with age may elucidate the mechanisms of decline in disease states.

Over the past 20 years, we have investigated the age-related mechanisms and alterations involved in this process, focusing on the role of RAS in the aging process. Recent studies have provided increasing evidence that AngII may also play an important role in aging $(5-7,23)$. We observed that SA- $\beta$-gal staining was significantly increased in the AngII-induced cells compared to the control cells. Cell cycle analysis showed that the cells were arrested in the $G_{0} / G_{1}$ phase, which indicates that AngII promoted cellular senescence in the GMCs. It has been reported that cells that have undergone replicative senescence in culture show distinctive changes in morphology, such as an
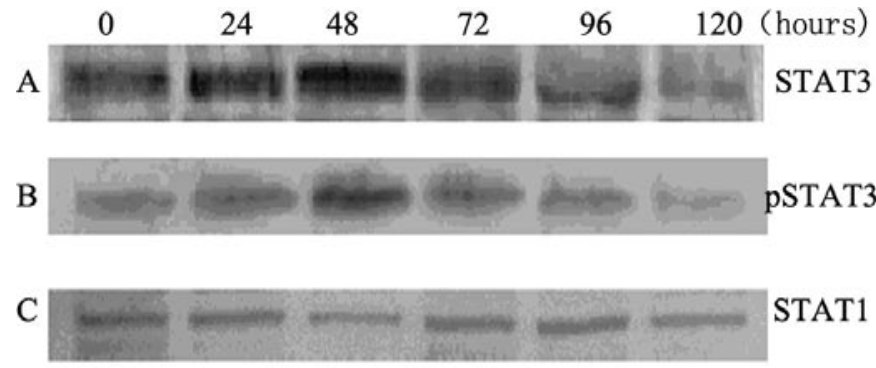

D

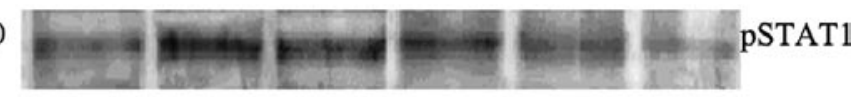

$\mathrm{E}$

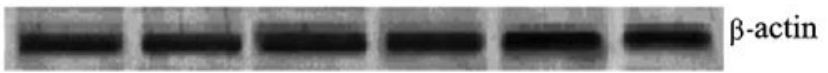

Figure 7. AngII selectively induced STAT activation in GMCs. The expression of STAT3, pSTAT3, STAT1 and pSTAT1 at each time point $(0,24,48$, 72,96 and $120 \mathrm{~h}$ ) was determined by Western blot analysis. The results are representative of three independent experiments carried out under the aforedescribed conditions.

enlarged cell morphology, polymorphic nuclei and vacuolization. These characteristics were apparent in our findings, thus indicating that AngII successfully induced GMC senescence and established a senescence model.

STAT expression during aging is the subject of some controversy. It has been reported that STAT3 and pSTAT3 expression is up-regulated in cultured human senescent fibroblasts (18) and aging T-cells (24); nevertheless, other studies have demonstrated their expression to be down-regulated with age in rat brain (24) and heart (20) cells. STAT1 and pSTAT1 expression is down-regulated in rat macrophage cells (25). These contradictory results could be explained on the basis of cell specificity and different aging rates between species and organs. In this regard, we observed STAT1, STAT3 and pSTAT1, pSTAT3 alterations during the process of GMC senescence induced by AngII. In agreement with our research, a great deal of evidence indicates the enhanced activity of a specific signaling transduction pathway contributing to aging. In the present study, to firmly elucidate the function of the JAK2/STAT signaling transduction pathway during aging, we observed alterations in cell morphology after exposure to AG490, the JAK2 blocker. Our results showed that senescence-related indices were ameliorated (cell viability was increased, cell cycle proportion was normalized, SA- $\beta$-gal positively stained cells were decreased, cell morphology and ultra-microstructure changes were reversed) in the AG490stimulated cells compared to the AngII-induced cells. This appeared to be due to the process of aging, and not to the AngII activation of the JAK2/STAT pathway, although this pathway can be activated by AngII in and of itself.

Consistent with a key role for AngII in age-related kidney disease are reports that AngII blockers attenuate the renal effects observed in aging. In the majority of cases, inhibition of RAS by ACEIs or ARBs has proved effective in improving renal structure and function in aging mice and rats $(26,27)$. Previous studies have demonstrated that chronic administration of losartan prevents age-associated changes in the rat kidney (28). In this regard, we observed the func- 
tion of losartan in delaying GMC aging. SA- $\beta$-gal staining was significantly decreased in the losartan-stimulated cells compared to the AngII-induced cells. Cell cycle analysis indicated that the number of cells in the $\mathrm{G}_{0} / \mathrm{G}_{1}$ phase was increased; morphology and ultra-microstructure changes such as enlarged cell morphology, polymorphic nuclei, vacuolization and invagination of the nuclear membrane were not apparent. These findings indicate that losartan may play a role in preventing GMC senescence.

To our knowledge, this is the first study demonstrating that AngII induces the cellular senescence of GMCs via the JAK/ STAT1/3 pathway. Although increasing evidence indicates that the signal transduction pathway is activated in aging tissues or cells, the role of JAK2/STAT in the GMC aging process is poorly understood. Further studies on the mechanisms leading to senescence using in vitro senescent cells may contribute to our understanding of the role of JAK2/STAT in the aging process. In summary, the data presented in this study demonstrate that AngII induces GMC senescence, whereas the induction of normal cell senescence may rely on the JAK2/STAT pathway. Therefore, a better understanding of the mechanisms by which AngII induces normal cell senescence would be beneficial to the development of new therapeutics, more effective in depleting aging cells and limiting toxicity to normal tissues.

\section{Acknowledgements}

This study was supported by a grant from the Major Basic Project of China (973), no. 2007CB507400. The authors wish to thank Merck for providing the losartan.

\section{References}

1. Jager KJ, van Dijk PC, Dekker FW, Stengel B, Simpson K and Briggs JD: The epidemic of aging in renal replacement therapy: an update on elderly patients and their outcomes. Clin Nephrol 60: 352-360, 2003.

2. Kiberd BA and Clase CM: Cumulative risk for developing end-stage renal disease in the US population. J Am Soc Nephrol 13: 163-164, 2002.

3. Agodoa LY and Eggers PW: Renal replacement therapy in the United States: data from the United States renal data system. Am J Kidney Dis 25: 119-133, 1995.

4. Port FK, Fenton SSA and Mazzuchi N: Introduction. ESRD throughout the world: morbidity, mortality and quality of life. Kidney Int 57: S1-S2, 2000.

5. Mukai Y, Shimokawa H, Higashi M, Morikawa K, Matoba T, Hiroki J, Kunihiro I, Talukder HM and Takeshita A: Inhibitor renin-angiotensin system ameliorates endothelial dysfunction associated with aging in rats. Arterioscler Thromb Vasc Biol 22: 1445-1450, 2002.

6. Kansui Y, Fujii K, Goto K, Abe I and Iida M: Ang II receptor antagonist improves a related endothelial dysfunction. J Hypertens 20: 439-446, 2002.

7. Imanishi T, Kobayashi K, Kuroi A, Ikejima H and Akasaka T: Pioglitazone inhibits angiotensin II-induced senescence of endothelial progenitor cell. Hypertens Res 3: 757-765, 2008.

8. Shan H, Bai X and Chen X: Angiotensin II induces endothelial cell senescence via the action of mitogen-activated protein kinases. Cell Biochem Funct 26: 459-466, 2008.

9. Herbert KE, Mistry Y, Hastings R, Poolman T, Niklason L and Williams B: Angiotensin II-mediated oxidative DNA damage accelerates cellular senescence in cultured human vascular smooth muscle cells via telomere-dependent and -independent pathways. Circ Res 102: 201-208, 2008.
10. Imanishi T, Hano $\mathrm{T}$ and Nishio I: Angiotensin II accelerates endothelial progenitor cell senescence through induction of oxidative stress. J Hypertens 23: 97-104, 2005.

11. Ma LJ, Nakamura S, Whitsitt JS, Marcantoni C, Davidson JM and Fogo AB: Regression of sclerosis in aging by an angiotensin inhibition-induced decrease in PAI-1. Kidney Int 58: 2425-2436, 2000.

12. Cruz CI, Ruiz-Torres P, del Moral RG, Rodríguez-Puyol M and Rodríguez-Puyol D: Age-related progressive renal fibrosis in rats and its prevention with ACE inhibitors and taurine. Am J Physiol. Renal Physiol 278: F122-F129, 2000.

13. Ferder L, Inserra F, Romano L, Ercole L and Pszenny V: Decreased glomerulosclerosis in aging by angiotensin converting-enzyme inhibition. J Am Soc Nephrol 5: 1147-1152, 1994.

14. Takeda K and Akira S: STAT family of transcription factors in cytokine-mediated biological responses. Cytokine Growth Factor Rev 11: 199-207, 2000.

15. Hirano T, Ishihara K and Hibi M: Roles of STAT3 in mediating the cell growth, differentiation and survival signals relayed through the IL-6 family of cytokine receptors. Oncogene 19: 2548-2556, 2000.

16. Wang TL, Yang YH, Chang H and Huang CR: Angiotensin II signals mechanical stretch-induced cardiac matrix metalloproteinase expression via JAK-STAT pathway. J Mol Cell Cardiol 37: 785-794, 2004.

17. Banes-Berceli AK, Shaw S, Ma G, Brands M, Eaton DC, Stern DM, Fulton D, Caldwell RW and Marrero MB: Effect of simvastain on high glucose and angiotensin II-induced activation of the JAK/STAT pathway in mesangial cells. Am J Physiol Renal Physiol 291: F116-F121, 2006.

18. Wang XD, Chen XM, Wang JZ, Hong Q, Feng Z, Fu B, Zhou F, Wang FY and Fan DM: Signal transducers and activators of transcription 3 mediates up-regulation of angiotensin II-induced tissue inhibitor of metalloproteinase- 1 expression in cultured human senescent fibroblasts. Chin Med J 119: 1094-1102, 2006.

19. Amiri F, Shaw S, Wang X, Tang J, Waller JL, Eaton DC and Marrero MB: Angiotensin II activation of the JAK/STAT pathway in mesangial cells is altered by high glucose. Kidney Int 61: 1605-1616, 2002

20. Boengler K, Hilfiker-Kleiner D, Drexler H, Heusch G and Schulz R: The myocardial JAK/STAT pathway: from protection to failure. Pharmacol Ther 120: 172-185, 2008.

21. Jung KY, Dean D, Jiang J, Gaylor S, Griffith WH, Burghardt RC and Parrish AR: Loss of N-cadherin and $\alpha$-catenin in the proximal tubules of aging male Fischer 344 rats. Mech Aging Dev 125: 445-453, 2004.

22. US Renal Data System: USRDS 2001 Annual Data System Report: Atlas of End-Stage Renal Disease in the United States. National Institute of Diabetes and Digestive and Kidney Diseases, Bethesda, MD, 2001.

23. Min LJ, Mogi M, Iwai M and Horiuchi M: Signaling mechanisms of angiotensin II in regulating vascular senescence. Ageing Res Rev 8: 113-121, 2009.

24. Fulop T, Larbi A, Douziech N, Levesque I, Varin A and Herbein G: Cytokine receptor signalling and aging. Mech Ageing Dev 127: 526-537, 2006.

25. Fortin CF, Larbi A, Dupuis G, Lesur O and Fülöp T Jr: GM-CSF activates the JAK/STAT pathway to rescue polymorphonuclear neutrophils from spontaneous apoptosis in young but not elderly individuals. Biogerontology 8: 173-187, 2007.

26. De Cavanagh EM, Inserra F, Ferder L and Fraga CG: Enalapril and captopril enhance glutathione dependent antioxidant defenses in mouse tissues. Am J Physiol 278: R572-R577, 2000.

27. Michel JB, Heudes D, Michel O, Poitevin P, Philippe M, Scalbert E, Corman B and Levy BI: Effect of chronic ANG I converting enzyme inhibition on aging processes. Kidney structure and function. Am J Physiol 267: R124-R135, 1994.

28. De Cavanagh EM, Piotrkowski B, Basso N, Stella I, Inserra F, Ferder L and Fraga CG: Enalapril and losartan attenuate mitochondrial dysfunction in aged rats. FASEB J 17: 1096-1098, 2003. 